\title{
The knowledge of pregnant women regarding appropriate oral hygiene practices of young children - a questionnaire survey
}

\author{
Magdalena Szalewska ${ }^{1}$, Monika Boryczko ${ }^{1}$, Anna Kapica ${ }^{1}$, Justyna Lemejda ${ }^{1}$, \\ Marta Lukasik ${ }^{1}$, Elzbieta Pietryka-Michalowska ${ }^{2}$, Jolanta Szymanska ${ }^{3 *}$ \\ ${ }^{1}$ Student Scientific Society at the Chair and Department of Paedodontics, Medical University of Lublin, Poland \\ ${ }^{2}$ Department of Mathematics and Medical Biostatistics, Medical University of Lublin, Poland \\ ${ }^{3}$ Patron of the Student Scientific Society at the Chair and Department of Paedodontics, Medical University of Lublin, Poland
}

\section{ARTICLE INFO \\ Received 16 April 2015}

Accepted 07 May 2015

\section{Keywords:}

pregnant women,

early childhood caries,

caries prophylaxis.

\begin{abstract}
Maintaining appropriate oral cavity hygiene in a young child is closely related to the health awareness and health-promoting behaviours of their parents/guardians, and especially that of the child's mother. The aim of the study was to evaluate the knowledge of pregnant women regarding best practice oral hygiene procedures in young children. The survey involved 327 pregnant women aged 16-49 years, and the tool utilized was an anonymous questionnaire survey. The questionnaire included seven one-choice questions concerning basic information on proper oral hygiene procedures as should be practiced by young children. The statistical analysis was performed using Statistica PROGRAM 10 (StatSoft). The results of the survey reveal $60.55 \%$ of all surveyed had correct knowledge with regard to appropriate cleaning practices for the toothless oral cavity of an infant, that concerning the beginning of tooth brushing $-70.03 \%$, tooth cleaning after night feeding $-39.76 \%$, the duration of tooth brushing (at least 3-4 minutes) - 43.12\%. What is more, the result of the survey demonstrate that slightly more than a half of the surveyed mothers $(53.82 \%)$ would encourage their children to brush their teeth on their own from the first year of age, while $18.35 \%$ believe that children should be assisted in tooth brushing at least to their eighth year of age, and 59.63\% would use fluoride toothpaste to brush their child's teeth before he or she is one year old. Of the participants in this survey, pregnant women with university education, those living in large cities, or who are older, and those who had had previous pregnancies, show greater knowledge regarding suitable oral hygiene practices among young children. Our results reveal that extensive application of modern information technologies can be a means of preventing early childhood caries by facilitating the transmission of knowledge on proper nutrition and oral hygiene practices among young children.
\end{abstract}

\section{INTRODUCTION}

The implementation of appropriate oral hygiene practices early in a child's life, immediately after the eruption of the first tooth, the use of fluoride-containing toothpaste, and effective permanent care procedures with regard to a young child's oral cavity, constitute several factors preventing the onset of early childhood caries (ECC) [6,13]. The study reveals the variability of parents' knowledge with respect to the basic principles of caries prophylactics in a young child $[1,5,10]$. It should be emphasized that the health status of

\footnotetext{
* Corresponding author

e-mail: szymanska.lublin@gmail.com
}

a child, including his or her oral health, depends primarily on the health awareness and behaviour of his or her mother.

\section{AIM}

The aim of the study was to evaluate the degree of knowledge held by pregnant women with regard to appropriate oral hygiene procedures in young children.

\section{MATERIAL AND METHODS}

An anonymous questionnaire survey was conducted among 327 pregnant women aged 16-49 years. The mean 
age of the respondents was $28.78 \pm 6.7$ years, and about half of the respondents were not older than 28 years $(\mathrm{Me}=28)$, most being 27 years of age $(\mathrm{Mo}=27)$. Furthermore, the age diversity among the surveyed was intermediate $-\mathrm{V}=21.45 \%$. In addition, the majority of the women lived in the country $45.57 \%(n=149)$; other respondents came from small cities (population below 50,000) - 28.75\% $(\mathrm{n}=94)$, cities with a population below $200,000-17.74 \%(n=58)$, and large cities (population over 200,000$)-7.95 \%(n=26)$. The education levels of the respondents include the following: university $-41.90 \%(n=137)$, general secondary $-16.82 \%(n=55)$, vocational secondary $-16.51 \%(n=54)$, post-secondary $9.80 \%(n=32)$, vocational $-8.26 \%(n=27)$, lower secondary (gymnasium) $-3.98 \%(n=13)$, and primary $-2.75 \%(n=9)$. Beyond the aforementioned, the number of previous pregnancies varied from 0 to $12(\mathrm{~V}=77.82 \%)$. The majority of women had previously had one pregnancy $(\mathrm{Mo}=1 ; \mathrm{n}=157)$, and the mean number of pregnancies in the studied population was $1.89 \pm 1.45$. The number of deliveries, however, varied from 0 to 8 , and the mean number of previous deliveries was $1.22 \pm 1.25$. Finally, $32.72 \%(n=107)$ of the respondents had not been mothers before.

The questionnaire included seven one-choice questions concerning basic information regarding appropriate oral hygiene procedures in young children. Statistical analysis was performed using Statistica PROGRAM 10 (StatSoft) [12].

\section{RESULTS}

In answering the first question, the respondents were asked to evaluate as true/false, the following statement: "Before the eruption of the first tooth, a child's gums should be cleaned with a soft swab soaked in warm, boiled water." Over a half of the women $-60.55 \%(n=198)$ believed that this information is true. The age of the women who evaluated the statement as true, varied from 16 to 49 years (mean age $29.21 \pm 5.74$ years), while the respondents who believed it false were from 18 to 47 years old (mean age $28.11 \pm$ 6.75 years). The observed differences were not statistically significant $(\mathrm{t}$-student $=1.58 ; \mathrm{df}=325 ; \mathrm{p}=0.114)$. A statistical analysis of the respondents' answers according to the place of residence did not show statistically significant differences $\left(\mathrm{Chi}^{2}\right.$ Pearson's $\left.=0.56 ; \mathrm{df}=3 ; \mathrm{p}=0.91\right)$. Also, education level did not exert a statistically significant influence on the answer choice. The women who believed the above statement true prevailed in each education category. The percentages of women in the individual education categories varied from $51.85 \%$ for the respondents with vocational education, to $65.69 \%$ for those with university education. The observed differences were not statistically significant $\left(\mathrm{Chi}^{2}\right.$ Pearson's $=3.98 ; \mathrm{df}=6 ; \mathrm{p}=0.68$ ). The number of previous pregnancies and deliveries also did not exert a statistically significant influence on the choice of answer.

The subsequent part of the paper discusses those of the analyzed parameters that showed a statistically significant relationship to the obtained answer. A detailed report on the statistical analysis, in the form of tables and figures, is available from the authors.
Regarding the question: "When is it necessary to start cleaning a child's teeth?", the respondents were asked to choose one out of five answers. The structure of the answers was as follows:

1. there is no need to clean them $-1.83 \%(n=6)$,

2. after the eruption of the first tooth $-70.03 \%(n=229)$,

3. after the eruption of all deciduous incisors $-12.54 \%$ $(n=41)$,

4. after the eruption of almost all deciduous teeth $-14.98 \%$ $(n=49)$,

5. only permanent teeth must be cleaned $-0.61 \%(n=2)$.

In further analyses, answer 1 - "there is no need to clean them" (deciduous teeth) and answer 5 - "only permanent teeth must be cleaned" were chosen to the same degree. Moreover, the choice of answer was statistically significantly related to the women's age. One-factor variance analysis showed that the mean age of women who selected the combined answers 1 and 5 was $28.88 \pm 3.83$ years, those who selected answer 2 were aged $29.49 \pm 6.16$ years, answer $3-27.12 \pm 5.95$ years, and answer $4-26.65 \pm 6.09$ years. The observed differences are statistically significant $(F=4.13 ; d f=3 ; p=0.007)$. Tukey's Honestly Significant Difference (HSD) test showed that the statistically significant age of women who believed tooth cleaning should be started after the first deciduous tooth eruption differs from the age of women who were convinced tooth cleaning should begin after the eruption of almost all deciduous teeth.

Another variable differentiating women as to their choice of answers was their education level. It was found that with an increase of education level, there was a decrease in the percentages of women who believed that only the permanent teeth of a child need be cleaned. Those percentages varied from $22.22 \%$ for women with primary education, to $1.85 \%$ for women with university education. At the same time, an increase was observed in the percentages of the respondents who were of the opinion that tooth cleaning should be started when the first deciduous tooth erupts - from $55.52 \%$, to $73.72 \%\left(\mathrm{Chi}^{2}\right.$ Pearson's $\left.=26.06 ; \mathrm{df}=18 ; \mathrm{p}=0.046\right)$.

A positive answer to the question: "Should a child's teeth be cleaned after night breastfeeding?" was obtained from $39.76 \%(n=130)$ of the respondents. No statistically significant relationships were found between the answer choice and the respondents' place of residence $\left(\mathrm{Chi}^{2}\right.$ Pearson's $=2.19$; $\mathrm{df}=3 ; \mathrm{p}=0.53$ ); the level of education also did not exert a statistically significant influence on the answer choice $\left(\mathrm{Chi}^{2}\right.$ Pearson's $=2.30 ; \mathrm{df}=3 ; \mathrm{p}=0.51$ ).

To the question: "How long should the child's teeth be brushed?" the respondents answered that brushing should last:

1. 1 minute $-21.71 \%(n=71)$,

2. not less than 2 minutes $-35.17 \%(n=115)$,

3. at least 3 minutes $-34.56 \%(n=113)$,

4. at least 4 minutes $-8.56 \%(n=28)$.

Pareto analysis of the collected study material showed that one factor: tooth brushing for over 3 minutes, may significantly (in $80 \%$ ) contribute to a decrease in the incidence of caries in children (Fig. 1). 


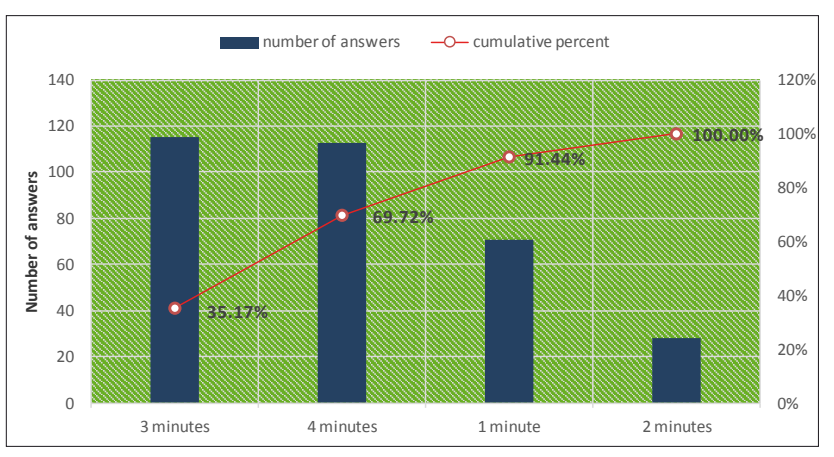

Figure 1. The results of the Pareto analysis

Regarding this question, education level exerted a statistically significant influence on the choice of answers $\left(\mathrm{Chi}^{2}\right.$ Pearson's $=19.97 ; \mathrm{df}=9 ; \mathrm{p}=0.018$ ). Along with an increase in the level of education, the percentages of women who believed that a child's teeth should be brushed for at least 3 minutes also increased. Also the number of deliveries affected the respondents' answer selection $\left(\mathrm{Chi}^{2}\right.$ Pearson's $=$ $28.61 ; \mathrm{df}=12 ; \mathrm{p}=0.0045)$. Women who had experienced several deliveries significantly more frequently believed that tooth-brushing time should not be shorter than 3 minutes.

The percentages of the answers to the question: "From what age should children be encouraged to clean their teeth on their own?" were the following: $3.06 \%(n=10)$ of the respondents believed that there is no need to encourage children to clean their teeth on their own, $53.82 \%(n=176)$ believed that the encouragement should begin from the first year of age, $23.13 \%(\mathrm{n}=92)$ - from the second year of age, and $14.98 \%(\mathrm{n}=49)$ - from the third year. Education level exerted a statistically significant influence on the choice of answer ( $\mathrm{Chi}^{2}$ Pearson's $\left.=19.55 ; \mathrm{df}=9 ; \mathrm{p}=0.021\right)$. It was found that with an increase in the level of education, the percentage of women who believed that there is no need to encourage children to brush their teeth on their own, decreased (from $4.08 \%$, to $0.73 \%$ ), while the percentage of women convinced that the encouragement should start from the first year of age, increased (from $44.95 \%$, to $60.58 \%$ ).

The answers to the fourth question: "To what age should children be assisted in tooth brushing?" were distributed as follows:

1. to the age of 2 years $-29.36 \%(n=96)$,

2. to the age of at least 4 years $-48.93 \%(n=160)$,

3 . to the age of at least 8 years $-18.35 \%(n=60)$,

4. there is no need to help children in tooth brushing $3.37 \%(\mathrm{n}=11)$.

No statistically significant differences were found between the selected answer and the place of residence $\left(\mathrm{Chi}^{2}\right.$ Pearson's $=7.05 ; \mathrm{df}=9 ; \mathrm{p}=0.63)$. Also education level $\left(\mathrm{Chi}^{2}\right.$ Pearson's $=16.50 ; \mathrm{df}=9 ; \mathrm{p}=0.057$ ) and the number of deliveries $\left(\mathrm{Chi}^{2}\right.$ Pearson's $\left.=17.41 ; \mathrm{df}=12 ; \mathrm{p}=0.135\right)$ did not exert a statistically significant influence on the answer choice.

To the question: "Should fluoride tooth paste be used in children younger than 1 years of age?", the majority of the women answered "yes" $-59.63 \%(\mathrm{n}=195)$, while other respondents $-40.37 \%(\mathrm{n}=132)$ believed that the tooth paste used should not contain fluoride. The variable that exerted a statistically significant influence on the answer choice was the respondents' place of residence $\left(\mathrm{Chi}^{2}\right.$ Pearson's $=12.91$; $\mathrm{df}=3 ; \mathrm{p}=0.005$ ). The respondents who had come from large cities (population over 200,000) significantly more often believed that the tooth paste employed should not contain fluoride $-73.08 \%$, while those who lived in villages, small cities (population up to 50,000) and medium-size urban areas (population up to 200,000) chose the answer that put forth that such toothpaste should contain fluoride (Fig. 2).

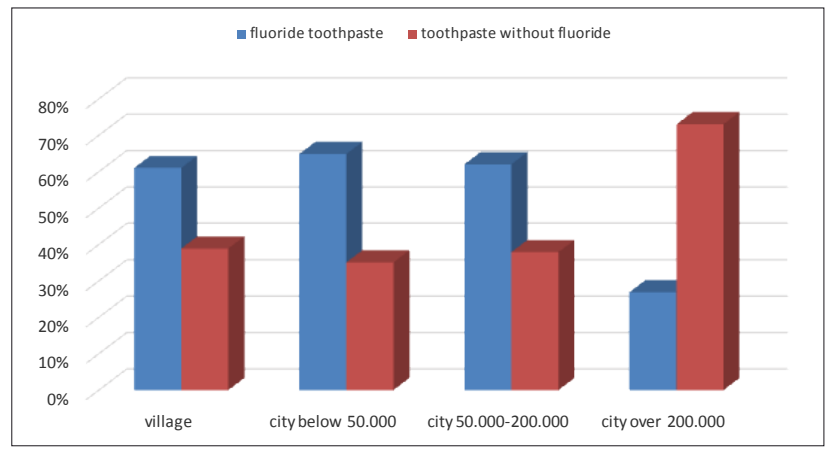

Figure 2. The influence of the place of residence on the choice of answer concerning the presence of fluoride in the toothpaste intended for use with children younger than 1 year of age

\section{DISCUSSION}

Poor nutritional habits and oral hygiene neglect in young children are the main causes of the high incidence and intensity of early childhood caries in the Polish population of children aged 71 months and younger (less than six years of age) $[14,15,18]$. It must be emphasized that the hygienic factors found to be significantly related to the prevalence and/or incidence of deciduous caries in children include: the age when tooth brushing began, correct brushing practices, participation of parents in tooth brushing (by monitoring or active partaking in the brushing procedure), frequency of tooth brushing during the day, neglect of tooth brushing before sleep, visible plaque and high gingival score [4].

In our study, older pregnant women, those with university education, those who are living in large cities, and those who had had more pregnancies, stood out from the other respondents. The aforementioned had greater knowledge of the basic principles of a young child oral hygiene than those within the latter group. It is common knowledge, however, that high health awareness does not automatically translate into health-promoting behaviours. This is also the case of parents/guardians and their attitudes towards the oral hygiene of their children. Extensive Australian studies showed that young, single, unemployed mothers were less likely to apply healthy behaviours or to improve their knowledge of healthy choices as a result of receiving oral health education [2], while nutritional and hygienic habits are related to the family's socioeconomic conditions and the education of both parents [8].

In the case of young children, monitoring or active participation of parents in tooth brushing, guarantees effective removal of dental plague $[4,16]$. It is disquieting that only $1 / 5$ of the respondents in our study knew that parents should monitor their child's tooth brushing and help him or her to do so, up to the eighth year of age.

Young children's teeth should be brushed twice daily with fluoride toothpaste. In the case of children aged 6-24 
months, the paste should contain 500 ppm of fluoride, and in the case of children aged 2-6 years - 1,000 ppm of fluoride, to prevent early childhood caries [3]. Our study showed that almost $60 \%$ of the future mothers believed the use of fluoride toothpaste before the first year of age to be appropriate. Other authors' research, however, found that the percentage of mothers applying fluoride toothpaste in their children was higher than that in our survey $[4,7,17]$.

Current literature indicates the effectiveness of prophylactic programmes concerning oral hygiene in young children [9]. Ramos-Gomez [11] emphasizes that the involvement of all mothers in prophylactic programmes may help prevent early childhood caries and its negative influence on children, families, and society, at the same time being relatively inexpensive. In addition, mothers indicated that the later stage of pregnancy was a good time to receive oral health education, many suggested that this should also be provided after birth at a time when teeth were a priority issue, such as when "baby teeth" start to erupt [2].

It seems, however, that a more general use of modern educational techniques in dental prophylactics should be considered so as to make the transmission of up-to-date health knowledge on young children nutrition and oral hygiene more attractive to future mothers. American studies show the effectiveness of a 30-minute PowerPoint and video presentation in improving oral health knowledge in parents looking after infants $-80 \%$ of parents said that the presentation they had attended was helpful, and that the information they received would change the way they took care of their child's teeth at home [17]. Hence, studies such as this confirm that modern methods using current information technologies are more effective than traditional methods of spreading dental health knowledge [1,17].

\section{CONCLUSIONS}

1. In the population of future mothers, pregnant women with university education, living in large cities, who are older, and those who had had more pregnancies, show greater knowledge on the oral hygiene of a young child.

2. The extensive application of modern information technologies may become a means to prevent early childhood caries by facilitating the transmission of best practice knowledge on the nutrition and oral hygiene of a young child.

\section{REFERENCES}

1. Ciok E., Grzebyta A., Maciejak D., Zadurska M.: Awareness of prophylaxis of disorders in stomatognathic system among pregnant women. Nowa Stomatologia, 18, 12, 2013.

2. Clifford H., Johnson N.W., Brown C., Battistutta D: When can oral health education begin? Relative effectiveness of three oral health education strategies starting pre-partum. Community Dent. Health., 29, 162, 2012.

3. European Academy of Paediatric Dentistry: Guidelines on the use of fluoride in children: an EAPD policy document. Eur. Arch. Paediatr. Dent., 10, 129, 2009.

4. Harris R., Nicoll A.D., Adair P.M., Pine C.M.: Risk factors for dental caries in young children: a systematic review of the literature. Community Dent. Health., 21(suppl 10), 71, 2004.

5. Iwanicka-Grzegorek E., Paluch M.: Knowledge about oral disease prevention of pregnant women - part II. Dental care of infant. Stomatol. Współcz., 18, 10, 2012.

6. Janas S., Olczak-Kowalczyk D., Wysocka M.: Rola lekarzy niestomatologów w zapobieganiu próchnicy wczesnego dzieciństwa. Nowa Pediatria, 1, 6, 2011.

7. Jiang E.M., Lo E.C., Chu C.H., Wong M.C.: Prevention of early childhood caries (ECC) through parental toothbrushing training and fluoride varnish application: a 24-month randomized controlled trial, J. Dent., 42, 1543, 2014

8. Manchanda K., Sampath N., Sarkar A.D.: Evaluating the effectiveness of oral health education program among mothers with 6-18 months children in prevention of early childhood caries. Contemp. Clin. Dent., 5, 478, 2014.

9. Plutzer K., Keirse M.J.N.: Influence of an intervention to prevent early childhood caries initiated before birth on children's use of dental services up to 7 years of age. Open Dent. J., 8, 104, 2014.

10. Pypeć J., Rogalska A., Zieleniewicz K., Mikołajczyk M.: Pregnant women's knowledge about prophylaxis of caries in children. Questionnaire. Przegl. Pediatr., 35, 211, 2005.

11. Ramos-Gomez F.: Early maternal exposure to children's oral health may be correlated with lower early childhood caries prevalence in their children. J. Evid. Based Dent. Pract., 12(suppl 13), 29, 2012.

12. Stanisz A. (2006). Przystępny kurs statystyki z zastosowaniem STATISTICA PL na przykładach z medycyny. Tom 1. Statystyki podstawowe. Kraków: Statsoft Polska.

13. Starczewska M., Emerich K.: Dental prophylaxis in children. Nowa Pediatr., 13, 28, 2010.

14. Szczepańska J., Szydłowska B., Lubowiedzka B. Pawłowska E.: Analiza czynników ryzyka występowania choroby próchnicowej u 3-letnich dzieci. Czas. Stomatol., 60, 162, 2007.

15. Tkaczuk M., Wiercioch-Klin B., Szymańska J.: Dobowa analiza żywienia dzieci z uwzględnieniem kariogenności stosowanych produktów spożywczych. Med. Ogól. Nauk Zdr., 18, 448, 2012.

16. Turska-Szybka A., Grudziąż-Sękowska J., Olczak-Kowalczyk D.: Czynniki ryzyka próchnicy wczesnego dzieciństwa i indywidualna ocena poziomu ryzyka na podstawie CAMBRA. Nowa Stomatologia, 3, 119, 2011.

17. Weber-Gasparoni K. et al: An effective psychoeducational intervention for early childhood caries prevention: Part II. Pediatr. Dent., 35, 247, 2013.

18. Wierzbicka M. et al.: Ogólnopolski Monitoring Zdrowia Jamy Ustnej i Jego Uwarunkowań. 2002. Ministerstwo Zdrowia 2003. 